AC 2010-2250: SENIOR DESIGN: A SIMPLE SET OF REPORT OUTLINES AND EVALUATION RUBRICS

Regina Hannemann, University of Kentucky 


\title{
Senior Design: A Simple Set of Report Outlines and Evaluation Rubrics
}

\begin{abstract}
To evaluate student performance in design courses is a challenging task. There are many different tools available and there are also a variety of tools being described in the literature. Most of these research papers focus on specific topics such as self/peer evaluation, choice of teams, choice of projects, and other very self contained aspects of design courses. This paper intends to show a set of report outlines along with evaluation tools and rubrics used in a onesemester senior design capstone course.
\end{abstract}

The author of this paper has taught the senior design capstone course in Electrical and Computer Engineering at the University of Kentucky for several years. During this time a set of reporting outlines for the students were developed. The course is offered as a one-semester class and the students need to write a proposal, a midterm executive summary, and a final report. For all of these reports the students are given an outline to follow. The students also need to hand in self/peer evaluations three times per semester. These self/peer evaluations have been adapted from different self/peer evaluations found on the Internet as well as experienced in FIE workshops. The author has adapted/developed evaluation rubrics to grade the reports and presentations. Finally a rubric to evaluate the students' performance and their projects on the final showcase has been developed. Graduate students, faculty, and industrial advisors have used this rubric now for several semesters to find the best-presented project of the showcase.

The author hopes that the full set of outlines along with evaluation rubrics stimulate ideas in the community to develop new and better means of teaching and evaluating the technical as well as professional skills needed by our graduating seniors.

\section{Introduction}

Senior Design or Capstone courses are common for most engineering degrees. These courses provide the students with a final larger project to apply the skills - technical and professional they have learned throughout their curriculum. Besides the obvious technical challenges the students usually face team issues as they are commonly forced to work in teams, as well as issues related to project management, written and oral communication and others. At some engineering schools like Olin College the curriculum is designed to train the students from the beginning in team oriented project work whereas at other schools like the University of Kentucky, where the author teaches, the curriculum is more traditionally formed and most of the courses are taught in pure lecture style with individual well defined assignments like homework, quizzes, and exams. Therefore, the final design course, which should be the "icing on the cake of the engineering education", puts students as well as educators at these schools into a very challenging situation. For the first time during their education the students are supposed to solve a larger open-ended technical problem. At the same time they have to learn how to produce well-written reports, give excellent presentations, manage their time, deal with team members, and so forth. And faculty is facing the task to ensure the students that they actually will need all these skills, provide them 
with enough information to handle all tasks, while not overloading the students. Finally, all these aspects have to be graded and most of us engineering educators are not necessarily the bestequipped persons to guide, grade, mentor, and intervene in team issues or writing.

The author has been teaching the Senior Design course at the University of Kentucky for four years now. During this time she has restructured the course, prepared the transition from a onesemester course to a two-semester sequence, which will take place in Fall 2010, and developed report outlines, self/peer evaluations, and grading/feedback rubrics for the course. Attending workshops at conferences, literature and Internet research, and last but not least help and feedback from numerous colleagues were used for this last task. This paper will present the most recent versions of these outlines, evaluations, and rubrics so other educators can use these as a resource for their own design courses.

A literature research reveals that most papers state the existence of outlines and grading rubrics, but do not describe any details of these (examples ${ }^{2,3}$ ). Bachnak ${ }^{4}$ gives an example for a peer presentation evaluation form and Meyer ${ }^{5}$ shows an evaluation rubric for a laboratory notebook. Report outlines can be found in Bruhn and Camp ${ }^{2}$ and in Bachnak ${ }^{4}$. The most detailed templates and outlines as well as a few grading rubrics the author found in Conrad et al. ${ }^{6}$ Self and Peer evaluations have been the biggest problem to the author. Finding/developing a meaningful rubric as well as developing a strategy to give feedback to the students has been a long and error prone process. Attending a workshop ${ }^{7}$ at the 2007 FIE conference helped to build a basic evaluation form, which was refined over the following years. The workshop did not give the author enough confidence to use the full assessment tool provided by the presenters, therefore only a very small portion has been adapted to the course at the University of Kentucky. From this perspective the author probably fits very well in the description of workshop attendees given by Montfort et al. ${ }^{8}$

In the next sections the author will describe the developed outlines, self/peer evaluation, and grading rubrics as used in the one semester senior design course at the University of Kentucky. In the paper itself the descriptions and usage will be given, the actual outlines and forms will be shown in the appendix.

\section{Background}

The ECE senior design course at the University of Kentucky is set up so that each team has an individual project. Here are some example projects:

- In-Camera 360 Degree Panoramic Imaging using CHDK

- IEEE hardware competition (SouthEastCon)

- Dual Controlled Heating and Ventilation Control System (HVAC)

- Solar Car: Battery Charger

- Solar Car: Maximum Power Point Tracker

- Solar Car: Motor Controller

- Meteor Detector

- Diffraction Grating Based Surface Plasmon Resonance Sensors

- Electric Bicycle

- Electrical Distribution System for the Harkness Edwards Vineyards 
As can be seen from this selection of projects (from three different semesters) the variety of project scopes is large. For any advisor/reviewer the task to compare these projects with each other to give appropriate feedback is impossible and each project has to be seen individually. Especially outside reviewers (faculty not involved in the project or industrial reviewers) will review the project reports given to them or the presentations they are listening to under a very individual viewpoint. Therefore, for the review process to be fair and efficient it is important that each reviewer reviews a set of projects as well as that each project is reviewed by a group of reviewers.

\section{Full Reports Outline}

The students have to write two full reports during the one semester course: a proposal about three weeks into the semester and a final report at the end of the semester. This is a team effort for the students and especially the proposal is one of the first big assignments for them. Not only need the students to understand as much of their project technically as possible to be able to write a meaningful report, this is also for most of them the first report longer than five pages they write during their curriculum. The outline tries to give them a template. The students are also provided with reports from previous semesters to have even more guidelines.

The final report has almost the same structure as the proposal. The students are expected to reuse their proposal write-up. The technical description is expected to be more elaborate than in the proposal and there is also the added section of a project reflection, which is not usually part of a technical report but should give the students the opportunity to reflect on their project and the work they have done during the semester.

For the past two semesters the students have been required to schedule feedback sessions with the Writing Center. The Writing Center assists students, faculty, and staff with the process of writing in any discipline and for any purpose. They usually offer free individual and group consultations on any writing project at any stage in the writing process. For our senior design course we have a special set up so that the teams will have a preferred time slot where they can set up their appointments with tutors. The Writing Center then also tries to set up the appointments for each team with the same tutor for each of the sessions they have to attend. The experience of these past two semesters shows an increase in better-written reports, mainly on the grammar and spelling aspect. Unfortunately, as most of the tutors at the Center are English majors with little technical background, they have problems to understand the jargon of the reports and are therefore sometimes not able to proofread the reports in a satisfying way.

Appendix A shows the outline of the proposal and appendix B shows the outline of the final report including all details, which have been omitted in appendix A.

\section{Design Review Executive Summary}

Around midterm a design review takes place. The writing of a full report takes up quite some time of the students; therefore they are required to write an Executive Summary at this time. The book $^{9}$ referred to in Appendix $\mathrm{C}$ is the writing book required for all students in the class. This book is mainly used as a reference book for the students. 


\section{Report Evaluation Rubrics}

Course advisor, the teams' faculty advisors, other faculty, and industrial advisors (others than industrial sponsors of projects) review all reports. For this purpose the evaluators are provided with the reports to review and a review rubric. This review rubric instructs the reviewer to rate certain topics of the report (writing, use of figures, feasibility of project etc.) in a range from 0 to 5, where

$0=$ Unacceptable

$1=$ Poor

$2=$ Acceptable

$3=$ Good (average work for entry-level engineers)

$4=$ Excellent (top 25\% for entry-level engineers)

$5=$ Outstanding (top 5\% for entry-level engineers)

The reviewers are also asked (especially for the proposal and midterm reviews) to provide the students with comments to improve their projects as well as their reports.

As stated in the background section, each report will be reviewed by a group of reviewers. This ensures that experts of the field as well as non-expert, but still electrical engineering reviewers will read through the report. Due to this process it is ensured that a variety of viewpoints is covered in the feedback process.

The report rubrics have been set up on purpose to be less student-friendly, but more industryfriendly. The industrial advisors are a mixed group of advisory board members of the department, which are mainly in higher management positions, having been responsible for hiring young graduates for their companies in the past, over recent graduates, to engineers recruited via the local IEEE section, which are senior engineers currently employed by local engineering companies as well as retired engineers. The background of these engineers allows them to rate the reports on the given scale quickly. All of these engineers have been tackling the task of writing reports themselves as well as reading reports of colleagues, employees etc and have a knowledge of what a good written report should look like.

The rubrics' questions

- Quality of Writing

- Appropriate Use of Figures and Diagrams

- Clarity of Project/Problem Description

- Relevance/ importance of Project's Scope

- Feasibility of Project's Scope

have been developed with feedback from these industrial advisors over the past years. The "Quality of Writing" criterion is the result of complaints of the industry in various surveys that engineering graduates often do not know how to write in clear English sentences. The "Appropriate Use of Figures and Diagram" criterion stems from the fact that the students have a tendency to write their reports with very little and sometimes no accompanying figures. A standard complaint from the industrial advisors is the lack of overall flow diagrams or overall block diagrams to give an overview of the project. The third criterion, "Clarity of Project/Problem Description", rates the ability of the students to "tell their story". Quite often 
they are not able to explain the basics of their own project. Unfortunately, as long as they have only a vague opinion of what they are supposed to develop in their project, they will not be able to explain nor will they be able to build a proper prototype for their project. Also, as the reviewers are such a mixed group, the students need to be able to explain their project to all of these reviewers and make sure they can explain the project in a way which is clear to experts as well as non-experts. "Relevance/ importance of Project's Scope" targets the students' ability to explain why they are building their project. In their reports the students are supposed to have background information and should have a conclusion out of this why their project is unique. Even though this part is not a marketing study and definitely cannot replace one, it is the (in marketing) untrained engineering student approach to argue the necessity of their project. Finally, the report rubrics include the "Feasibility of Project's Scope". This will give feedback to the students if the project as described in their report is feasible in the eyes of experienced engineers.

Experience shows that the report feedbacks give valuable information to the students as most reviewers give the numbered rating as well as provide comments to the students on how to improve their reports and their projects. The feedback sheets as submitted by the reviewers are given to the students. For grading purposes the numeric values are curved, as we cannot expect all of our students to be outstanding, top 5\% percent of entry-level engineers. To be in the "A" grade range it is expected that they would be in the "Excellent" range and 20 points of a review sheet will be counted as $100 \%$, when the ratings are translated into grades.

The evaluation rubrics can be found in appendix D-F.

\section{Presentation Evaluation Form}

All teams have to give a proposal presentation around the same time their proposal report is due. They also have to give a design review presentation around midterm. Both of these presentations are team efforts; all students of a team have to present a portion of the presentation. As currently all presentations are held during class time, the time limit per presentation is 12 minutes plus 3 minutes discussion. This extremely short time (divided by three or four speakers, depending on the team size) makes it very hard to give individual presentation grades.

Other faculty, graduate students and/or industrial advisors help with the presentation grading. The form for this is given in appendix G. Most evaluators will give team ratings, only if one students is way better or worse in his or her presentation, they will give a student specific rating.

Especially for the proposal presentation the course advisor will concentrate on the presentation style of each individual student. Therefore, the students will get individual ratings from the course advisor. The notes on the presentation style taken during the presentation will then be used to give each student an individual feedback on how to improve for future presentations.

\section{Student Laboratory Notebook Evaluation Form}

All students in the course need to keep individual laboratory notebooks. These notebooks will be checked three times per semester and are rated with the help of the evaluation form in appendix 
H. The evaluation is separated in three parts: Overall Form, Thoroughness, and Creativity and Insight.

The first part rates the overall form. It will be checked if the students have bound notebooks, number the pages, write in ink etc.

The second part evaluates the student's thoroughness. Do they have a cogent sequence of activities and meetings? Are there design ideas? Is there any data collection? This includes the check for activities as a group as well as for the individual. For the data collection aspect the course advisor will check for measurements (is the set up noted, are the units present, could somebody else perform the same measurement using the given notes?), calculations (is there evidence why certain parts were chosen?), literature research (books, data sheets, web sites given?).

The third part, Creativity and Insight, is the most subjective of the three and gives room for many discussions with the students. Here the course advisor would like to see evidence that the student keeps the overall project in mind and can connect an initial idea with the overall goal. Is the student only working on one little aspect given to him or her by the other team members or is the student fully aware of the overall project and able to connect his or her own ideas with the parts the other team members are working on? Is there an overall design evident?

\section{ECE Senior Design Day Judging Form}

The University of Kentucky ECE Senior Design Course culminates in a daylong exhibit, where the students present their projects along with posters to faculty, students, industry, and the general public. At this exhibit the students will be judged on their projects. The judges talk to all teams and give ratings for the project as well as for the individual student performance.

As the report evaluations, this judging form also is based on a $0-5$ Likert scale with

$0=$ Unacceptable

$1=$ Poor

$2=$ Acceptable

$3=$ Good (average work for entry-level engineers)

$4=$ Excellent (top $25 \%$ for entry-level engineers)

$5=$ Outstanding (top 5\% for entry-level engineers)

This scale has been changed most recently from a $0-100 \%$ scale as there were several confusions. Judges who had read reports before used the $0-5$ scale anyway, as they obviously did not read the instructions. Other judges spent a lot of time deciding whether they should give one team a 83 or 85 compared to the 87 they gave another team. Using this "integer scale" seems to make the judges' and the organizers' life easier.

The teams have to present a poster displaying their work and also (if transportable) the prototype of their project. Teams having worked on a project, which does not allow them to bring their prototype in, like the "Electrical Distribution System for the Harkness Edwards Vineyards", will usually document their work with pictures and movies. 
The criterions to be judged for the project are:

- Innovation and Creativity of the Project

- Poster Board Content and Organization

- Demo of Project

- Overall Project Rating

- Difficulty of Project

Most of these criteria are self-explaining. In "Demo of the Project" the judges also will give good ratings if the prototype is not yet fully functioning but the students are able to explain what the reason for this is and also are able to explain, how they would overcome the problems if they would be given more time. In "Innovation and Creativity of the Project" the judges will look for evidence that the students did actually put design effort in the project and did not only plug together components bought off the shelf. As the poster is a new form to present their project, the team will also be rated on the poster design. The judges will look for information relevant to the project; they also would like to see evidence of the design process on these posters. Finally the judges will give an overall project rating. As in the past this led to discussions on how to rate the projects with respect to each other, the "Difficulty of the Project" criterion has been introduced. Thus the judges can give an overall project rating just for this project, but can also express their opinion on how hard to tackle this project has been.

The individual students will be rated on their "Presentation Skills" and their "Knowledge of the Project". Each student will receive an overall rating from each judge. Most judges will only check if the student can explain a part of the project and if they contribute to the overall presentation of the project. Other judges have a tendency to deeply question the students on which parts on the project they have worked on, how did they contribute to the overall result etc.

All ratings given by the judges will influence the "Final Presentation Grade" for each team and student. For the Senior Design Day itself the three top scoring teams under the aspect of innovation will be the winners of the day and receive certificates for their achievement.

This judging form can be seen in appendix I.

\section{Self/Peer Evaluation}

As mentioned in the introduction the author had the most problems finding a meaningful way to perform self/peer evaluations. The evaluation form given in appendix $\mathrm{J}$, is the result of many Internet researches, workshop attendances, feedback from colleagues and students. This evaluation is now given three times per semester, first at midterm, halfway between midterm and finals week, and a last time a few days before ECE Senior Design Day. Each time the students are provided individual feedback for their self/peer evaluation. During this session also possible strategies are discussed to improve individual and team performance.

The form consists of three major parts. In the first part the students are asked to rate their teammates and themselves on three aspects:

- Quality of Work 
- $\quad$ Team Membership

- Communications

Each of these three aspects is rated on a 1-7 Likert Scale. The "1" is the lowest score and indicates that the team member has basically dropped out of the team and is not contributing at all anymore. " 2 ", " 3 ", and "4" are step wise indicating more interaction with the team and the project and more quality of work. The " 5 " indicates a good team member, contributing to work, attending meetings, communicating well. The " 6 " will be a team member who is up to speed; who performs as promised, delivers quality work and does well on documentation and communication with team and advisors. The "7" is the outstanding team member, who is going out of his or her way to contribute to the project and the team's goals.

The second and third parts of the self/peer evaluation form try to assess the member and team effectiveness. First the students have to identify the relative contributions of each team member on the aspects of time and value. This is done on a scale of $100 \%$ and the students have to split up which team member contributes how much effort to time and value of the project. This part works fairly well, even though some students have a tendency to equal time and effort and do not distinguish between these or - even worse - do not even recognize the difference of these two aspects delivered to a project.

The third part of the self/peer evaluation is the newest part added. Again it tries to evaluate the member/team effectiveness. In this part the students are asked to identify a strength and an area to improve for each team member. Strength and area to improve are explicitly to be chosen from a non-technical area.

This reflective part is still very hard for the students. First of all, a lot of students have a problem to identify a strength/weakness other than technical. If they find the strength/weakness, they are struggling to formulate the descriptions. As we use this part of the feedback more often the author hopes to stimulate better answers from the students, which gives then each student the opportunity to actually grow in their personal and professional skills.

\section{Conclusion}

Overall, these tools have been very helpful to assess the students' performance in the senior design course over the past years. The tools are constantly developed further and adapted to the needs of the course. For the next steps, as the course will go through the change to a twosemester sequence, starting next fall, the frequency of the assessment will change and with that most likely some of the assessment tools will need to be adapted again.

\section{Bibliography}

1. http://scope.olin.edu/

2. Bruhn, Russel and Camp, Judy, "Creating Corporate World Experience in Capstone Courses," Proceedings of the 2004 Frontiers in Education Conference, Savannah, GA, 20 - 23 October 2004

3. Ford, Ralph M. and Lasher, William C., "Process For Ensuring Quality Capstone Design Projects," Proceedings of the 2004 Frontiers in Education Conference, Savannah, GA, 20 - 23 October 2004

4. Bachnak, Rafik, An Approach for Successful Capstone Projects," Proceedings of the 2005 Frontiers in Education Conference, Indianapolis, IN, 19 - 22 October 2005 
5. Meyer, David G., "Capstone Design Outcome Assessment: Instruments for Quantitative Evaluation," Proceedings of the 2005 Frontiers in Education Conference, Indianapolis, IN, 19 - 22 October 2005

6. Conrad, James and Hoch, Daniel and Skinner, Frank, "Student Deliverables and Instruction for a Senior Design Program Course," Proceedings of the 2007 ASEE Conference, Honolulu, Hawaii, 24 - 27 June 2007

7. Davis, Denny and Trevisan, Michael and Beyerlein, Steven and Thompson, Phillip and Harrison, Kunle, "Workshop - Capstone Engineering Design Assessment Workshop," Proceedings of the 2007 Frontiers in Education Conference, Milwaukee, WI, 10 - 13 October 2007

8. Montfort, Devlin and Brown, Shane and Pegg, Jerine M., "An Investigation of the Adoption of an Assessment Instrument for Capstone Design Courses," Proceedings of the 2009 Frontiers in Education Conference, San Antonio, TX, 18 - 21 October 2009

9. Beer, David and McMurrey, David, “A Guide to writing as an Engineer," Wiley, $3^{\text {rd }}$ edition, 2009

\section{Appendix A Proposal Outline (Excerpt)}

The white paper or pre-proposal is probably the most common way that contracts are made. Industrial ventures are often based on the white paper alone, rendered into a full proposal or contract with deliverables, timetables and costs. Government agencies will usually solicit white papers as a predecessor to a full proposal. Many times the deal is made at the white paper level and what follows is simply formality.

In this task you are to write a proposal about the senior design project you want to do this semester. Turn it in electronically in pdf (preferred) or MSWord format. Also turn in a paper version.

Suggested Proposal Outline

Suggested means that almost all of these parts should appear. You can add or slightly change but overall you should follow these guidelines.

1. Title Page

2. Abstract or Summary of your idea

3. Introduction

4. Background

5. Impact Statement

6. Technical Descriptions

7. Time Line

8. Distribution of Effort

9. Deliverables

10. References

11. Budget/Parts List

12. Biographical Sketches

\section{Appendix B Final Report Outline}

The "Technical Report" is a common way to document projects.

In this task you are to write a final report about the senior design project you are doing this semester. Turn it in electronically in pdf (preferred) or MSWord format. Also turn in a paper version on ECE Senior Design Day. 
Suggested Final Report Outline

Suggested means that almost all of these parts should appear. You can add or slightly change but overall you should follow these guidelines. The table of contents below gives you all suggested chapter headings. Only the last one $\backslash$ Miscellaneous Items" should not appear in your report but contains general information on how to format your report.

Under each subsection in these guidelines you find hints what you should/could put into these parts in your report. Please note that some of them are not necessarily parts which belong into a technical report but rather are parts I need from you as a reflection on your work in this class. Remember that you wrote most of these parts already in the proposal. Take that report as a basis for this final report. Change where new parts have to be added. Change where recommended by reviewers. Change wherever you think it is needed to adapt the proposal to the final state of your project (timeline etc, but also tense of writing: instead of $\backslash$ we want to build..." you report what has actually been done.) Add where it is needed to describe your present state of the project.

Please be aware that I have added some "chapters" to this report compared to the proposal.

1. Title Page

2. Abstract or Summary of your idea

3. Introduction

4. Background

5. Impact Statement

6. Technical Descriptions

7. Time Line

8. Distribution of Effort

9. Deliverables

10. Possible Future Work

11. References

12. Budget/Parts List

13. Acknowledgements

14. Biographical Sketches

15. Project Reflection

Title Page

- Name of project

- Names of students

- Contact Info

- Date

- Faculty Advisor (and association)

- Industry Advisor (and association) (if applicable)

- Class Advisor

Abstract or Summary 
- Be descriptive, not technical

- What is the problem you are solving

- How are you solving it (remember to be descriptive)

- Why is your solution so amazing?

Introduction

- Historical perspective of how it has been done up to your idea

- Present your idea and why it is innovate

- Describe the contents of your final report, approximately 1 sentence per section.

\section{Background}

- Describe other methods

- Describe known techniques or technology related concepts to partially educate the reviewer to understand your proposed scheme.

Impact Statement

- How does it fit in with existing technologies?

- How does it fit in to the Market

- Manufacturing issues

- Social and Environmental Impact

Technical Descriptions

This should be the biggest part of your report. Choose some subsections to structure this part. Figures and charts are always a good idea in this part of the report. Remember to label the figures and to mention them in the text. If the figures are too big, you might consider putting them into an appendix.

- Provide system level flow chart and description on how it works

- Provide performance criterion and expected or target performance

- Provide complete schematics

- Provide mathematical definitions of filters and electronic devices

- Provide logic diagrams

Time Line

- Organize by week and indicate team member responsible

- Use Table or Gantt chart (Gantt chart seems to be more used in industry)

- Indicate Milestones and important objectives

- Contrast this with your proposed deadline and explain any inconsistencies or delays

- Please compare to your original proposal, indicate why you have changed your time-line/ planned work

- Then compare to your midterm timeline, indicate, if you met the timeline, if not, why? 


\section{Distribution of Effort}

- What is each group member responsible for in terms of project?

- What is each group member's background that makes him or her well suited for their effort?

- Add a paragraph, if this worked out well or not (this is not what you would have in an industrial report, but should give you some reflection on how you distributed your work and if it was a wise choice.)

Deliverables

- Organize by date

- Associate with milestones

- Have more deliverables as indicated from the syllabus, e.g. indicate when a certain circuit or code part has to be shown to team and faculty advisor

- Where all milestones met? If not, why? If delayed, why?

\section{Possible Future Work}

Is your project finished? If not what could be done to improve it? Would that be a suitable project for one or more future senior design teams (one or two semester)?

\section{References}

Look up appropriate way to reference these! Give numbers, cite numbers in text, give specific pages from book, specific web site, indicate year (especially also on web sites, remember in a year from now this website might have vanished). Wikipedia is not a valid reference! It might be a first start to look things up, but then you have to go ahead and find more reliable references.

- Books

- Articles

- Web sites

- Data books

\section{Budget/Parts List}

- Refer to schematics and provide a complete parts list

- Provide a budget for the project and indicate whether or not it is for a single unit or multiple units

- Indicate (here or in the technical description) why you have chosen certain over others you had in the proposal

- Important (Since it was missing in all proposals one semester): Give a total!

- Describe (where applicable) whether these costs are for the prototype or for anticipated for mass production. If possible have two budgets. One for the prototype and one for mass production. 
Acknowledgements

- Note any financial support for your project

- Note your advisors help

- Note help of anyone who helped you with your project

\section{Biographical Sketches}

Written in 3rd person. List educational and professional achievements and background. These are usually listed in reverse chronological order and the bio is ended with a 1 or 2 sentence description of present $R \& D$ interests.

\section{Project Reflection}

This again is not part of a technical report but is required for this class. In this part I would like to know your thoughts about the project. Where did it go well, where did you run in problems. Any suggestions if these and how these problems might have been avoided? If you would have to start all over again, what would you have done different? Is there anything you would have liked to have as a "lecture" or workshop you think would have helped you to do a better job on your project? This is not meant to be a part like, but if such and such would have done his/her work earlier we would have run into way less problems.... Please have constructive critique in this part, do not dish out anything you have been unhappy with in this last minute.

This reflection should be a reflection as the team. If anyone would like to hand in a page (or how much you would like to write) as reflections on your own, which you do not want to share with your team necessarily, please feel free to do so. This would also be the place to tell me why you think that certain tasks where not done by yourself or your team mates and what you think the reason is for not doing so. Please do not put these individual reflections into the final report, hand/send them in individually.

Miscellaneous Items

- Except for historical discussions, everything should be 3rd person and present tense.

- All figures have captions and all captions are cited. This means: All figures have a number and a caption (more than just figure 3, put some explanation that anybody who just looks at the figure understands what is displayed). All these figures have to be mentioned in the text. Put in only relevant pictures. In a technical report a picture of you all soldering the parts together might look amusing to you but is not professional. If you want to do any of these pictures, please do so in the "Project Reflection" part. And then the same rules as for all the other figures apply: number, caption, and mention in text.

- All tables need numbers, captions and mentioning in the text.

- All equations have numbers and have to be mentioned and explained in the text. 


\section{Appendix C Design Review Executive Summary Outline}

For your design review you will have to write an Executive Summary. Please read the book p $133,134$.

You are not asked to write a full report and then accompany it with an executive summary but to write only the executive summary.

Formalities:

- $\quad$ Between 2 and 3 pages long

- Use a 12 pt font

- Single spaced

- Alignment: justified

- No pictures in the summary, if you need a picture to explain your project (overall block diagrams are always liked by reviewers) add 1 page for figures

- Title: 14 point, bold

- Beneath title: team members (12pt)

- Beneath team: faculty advisor, industrial advisors (if applicable), course coordinator (12pt) (Please use appropriate titles)

Content:

- What is your project about

- Your chosen approach

- The status of the project

- What is the biggest challenge, how do you tackle it

- What are the testing procedures you have lined up to proof the "correctness" of your prototype?

\section{Appendix D Evaluation Rubric: Proposal}

Evaluation Rubric for Proposal Assignment (general project/problem description):

Project:

Advisor:

Group Members:

Please rate the project categories on a scale from 0 to 5 where:

$0=$ Unacceptable

$1=$ Poor

$2=$ Acceptable

$3=$ Good (average work for entry level engineers)

$4=$ Excellent (top 25\% for entry level engineers)

$5=$ Outstanding (top 5\% for entry level engineers)

1. Quality of Writing $\quad \begin{array}{lllllll}0 & 1 & 2 & 3 & 4 & 5\end{array}$

2. Appropriate Use of Figures and Diagrams $\quad \begin{array}{lllllll}0 & 1 & 2 & 3 & 4 & 5\end{array}$ 
3. Clarity of Project/Problem Description $\begin{array}{lllllll}0 & 1 & 2 & 3 & 4 & 5\end{array}$

4. Relevance/ importance of Project's Scope $\begin{array}{lllllll}0 & 1 & 2 & 3 & 4 & 5\end{array}$

$\begin{array}{llllllll}\text { 5. Feasibility of Project's Scope } & 0 & 1 & 2 & 3 & 4 & 5\end{array}$

Provide comments and suggestions that can help the students in writing their design review and in formulating realistic design constraints:

\section{Appendix E Evaluation Rubric: Design Review Executive Summary}

Evaluation Rubric for Design Review Executive Summary:

$[\ldots]$ Same header as proposal rubric $[\ldots]$

1. Quality of Writing $\quad \begin{array}{lllllll}0 & 1 & 2 & 3 & 4 & 5\end{array}$

2. Clarity of Project/Problem Description $\begin{array}{lllllll}0 & 1 & 2 & 3 & 4 & 5\end{array}$

3. Relevance/ importance of Project's Scope $\begin{array}{llllllll}0 & 1 & 2 & 3 & 4 & 5\end{array}$

4. Feasibility of Project's Scope $\quad \begin{array}{lllllll}0 & 1 & 2 & 3 & 4 & 5\end{array}$

Provide comments and suggestions that can help the students in writing their final report. For the more, give them hints on how they maybe can avoid running into troubles to finish their projects.

\section{Appendix F Evaluation Rubric: Final Report}

Evaluation Rubric for Final Report Assignment (general project/problem description):

$[\ldots]$ Same header as proposal rubric $[\ldots]$

$\begin{array}{llllllll}\text { 1. Quality of Writing } & 0 & 1 & 2 & 3 & 4 & 5\end{array}$

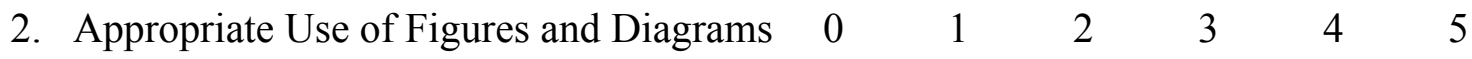

3. Clarity of Project/Problem Description $\quad \begin{array}{lllllll}0 & 1 & 2 & 3 & 4 & 5\end{array}$

$\begin{array}{llllllll}\text { 4. Report Complete and Precise } & 0 & 1 & 2 & 3 & 4 & 5\end{array}$

5. Feasibility of Project's Scope $\quad \begin{array}{lllllll}0 & 1 & 2 & 3 & 4 & 5\end{array}$ 


\section{Appendix G Evaluation Form: Presentations}

Presentation Evaluation

Group

Give either points to individuals or to the group in total

Presentation (25)

Eye Contact

Voice Projection

Posture

Use and Quality of Visuals or Extra Materials

Ability to Answer Questions (Accuracy, Ability to Infer/Hypothesize, Brief)
Articulation

Gestures

Appropriate Vocabulary
Date

Evaluator

\section{Content (50)}

Technical Relevance

Accurate Information

Research Effort

Enough Information

Appropriate Vocabulary 


\section{Appendix H Evaluation Form: Student Laboratory Notebooks}

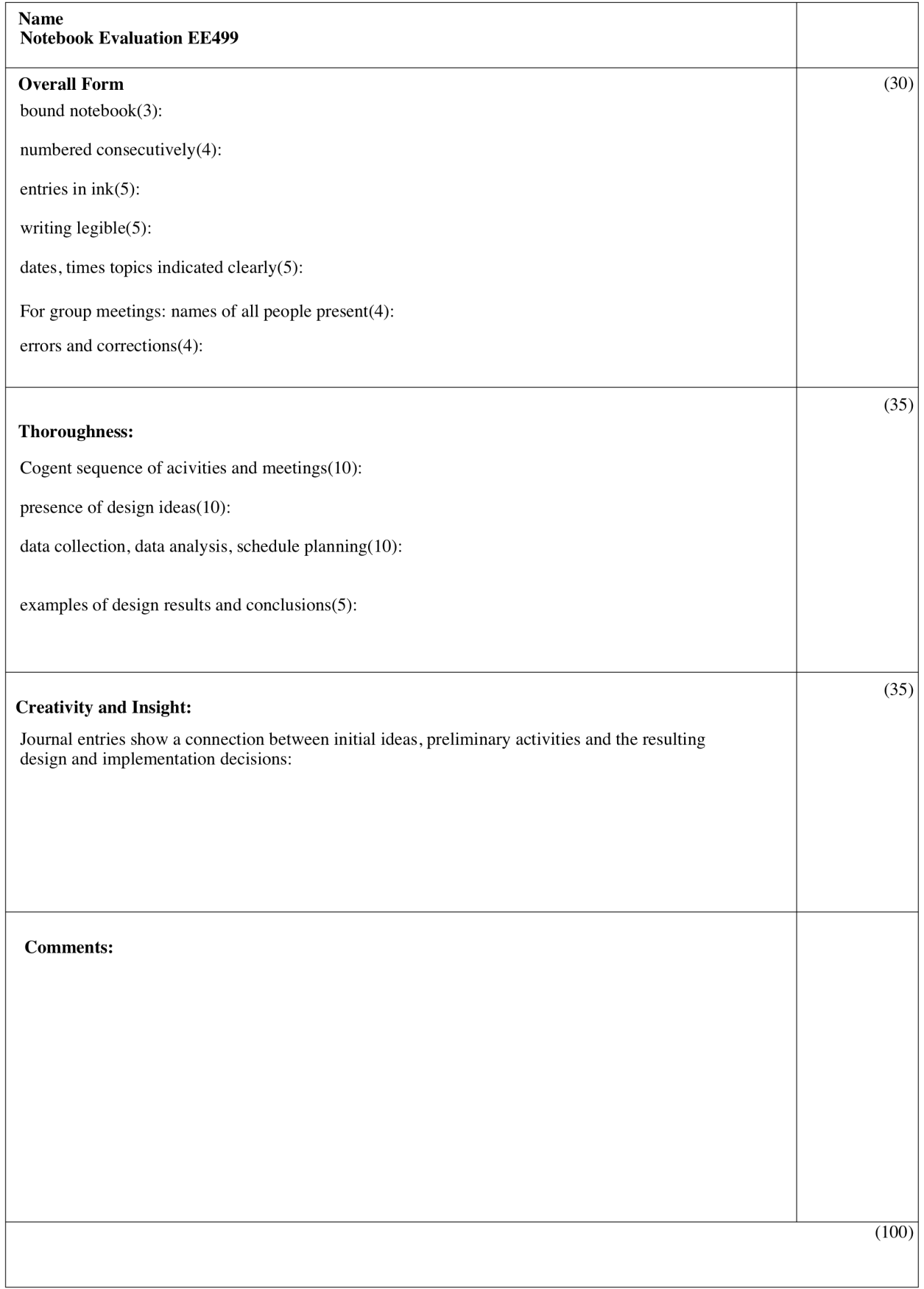




\section{Appendix I ECE Senior Design Day Judging Form}

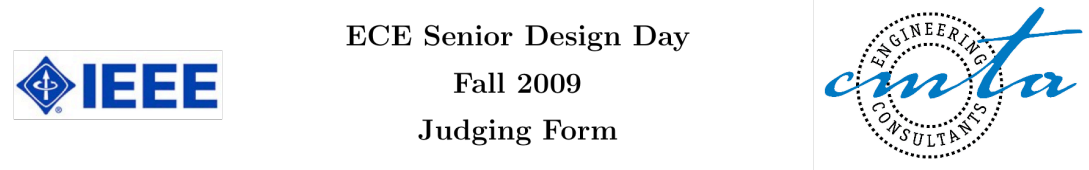

Project name:

Judge Name:

Please rate the project categories on a scale from 0 to 5 where:

$0=$ Unacceptable

$1=$ Poor

$2=$ Acceptable

$3=$ Good (average work for entry level engineers)

$4=$ Excellent (top 25\% for entry level engineers)

$5=$ Outstanding (top 5\% for entry level engineers)

Project Rating:

Innovation and Creativity of Project:

$\begin{array}{llllll}0 & 1 & 2 & 3 & 4 & 5\end{array}$

Poster Board Content and Organization:

$\begin{array}{llllll}0 & 1 & 2 & 3 & 4 & 5\end{array}$

Demo of Project:

$\begin{array}{llllll}0 & 1 & 2 & 3 & 4 & 5\end{array}$

Overall Project Rating:

$\begin{array}{llllll}0 & 1 & 2 & 3 & 4 & 5\end{array}$

Difficulty of Project:

$\begin{array}{llllll}0 & 1 & 2 & 3 & 4 & 5\end{array}$

Student Ratings:

\begin{tabular}{|c|c|c|c|c|c|c|c|c|c|c|c|c|c|c|c|c|c|}
\hline student name & & se & ta & io & $n \mathrm{~S}$ & kills & Kno & Jle & & & & & & \multicolumn{4}{|c|}{ Overall } \\
\hline 1. & 0 & 1 & 2 & : & 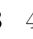 & 45 & 0 & 1 & 2 & & & 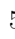 & 5 & 1 & 2 & 3 & 45 \\
\hline 2. & 0 & 1 & 2 & 3 & 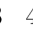 & 5 & 0 & 1 & 2 & & & s & 5 & 1 & 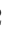 & 3 & 45 \\
\hline 3. & 0 & 1 & 2 & 3 & 3 & 5 & 0 & 1 & 2 & & & & 5 & 1 & 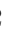 & 3 & 45 \\
\hline 4. & 0 & 1 & 2 & : & 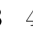 & 5 & 0 & 1 & 2 & & & & 5 & 1 & & 3 & 45 \\
\hline
\end{tabular}

Comments: 


\section{Appendix J Self/Peer Evaluation Form}

Personnel reviews are a part of project management responsibilities. You will be having regular reviews with your boss and will need to provide reviews of those you supervise. This is really a hard, but necessary, thing to do. To give you some practice we are asking you to do this for yourself and your team members.

Remember, that giving good grades to yourself and your teammates "just to give them/yourself good grades" does not help them/you at all to improve their/your behavior and input to the project. Be honest with yourself and your teammates and ask them to do the same for you.

\section{Rating Guidelines}

You can decide how to rate yourself and your team members on a scale from 1 through 7 in the following three areas, but here are some thoughts you might consider to help you come up with a rating (If you give a rating of 1 or 7 , please justify):

Quality of Work:

1. Has basically dropped out from the project and is not contributing in any way.

2. Has done minimal work or very poor quality work.

3 . Doing the minimum to get by, work is of marginal quality.

4. Work and accomplishment are lagging what is needed.

5. Work and progress on the project are good.

6 . Is doing very good work; does what is promised.

7. Has done exceptional work consistently and reliably. Exceed expectations.

Team Membership:

1. Has basically dropped out from the project and is not contributing in anyway.

2. Works separately with little or no interaction with the team.

3. Does not contribute to the overall team effort.

4. Only sporadic team interaction; has not been effective in providing a team solution.

5. Effective worker; team interaction is adequate.

6. Is a helpful team member; contributes time and effort to solving problems; participates in team meetings.

7. Has been an integral and important team member; has made significant contributions to the overall solution; attends and participates in all team meetings.

Communications:

1. Has basically dropped out from the project and is not contributing in any way.

2. Produces no useful documentation of work done; communication skills poor.

3. Documentation and communication skills are below expectations.

4. Documentation is only marginally helpful; communication skills need improvement.

5. Documentation and communication skill are adequate.

6. Documents all work; communicates effectively with the team and faculty advisor.

7. Documents work exceptionally well; has exceptional communication skills. 
Member/Team Effectiveness

In this part you have two assignments:

1. Identify relative contributions of each team member to project achievements

2. For each team member please provide a short description of two non-technical contributions to the team

(a) Strength (provide a label/descriptive word and how this is used to contribute to team effectiveness)

(b) Area to Improve (provide a label/descriptive word and suggests steps to achieve desired improvement in this area)

This should be done for all team members including yourself. 
Self/Peer Review

Project Name:

My Name:

Self Review

My grade: (Circle one in each category)

\begin{tabular}{|l|l|l|l|l|l|l|l|}
\hline Quality of Work: & 1 & 2 & 3 & 4 & 5 & 6 & 7 \\
\hline Team & &
\end{tabular}

\begin{tabular}{|l|l|l|l|l|l|l|l|}
\hline Team Membership: & 1 & 2 & 3 & 4 & 5 & 6 & 7 \\
\hline Comm
\end{tabular}

\begin{tabular}{l|l|l|l|l|l|l|l|}
\hline Communications: & 1 & 2 & 3 & 4 & 5 & 6 & 7 \\
\hline
\end{tabular}

If you gave a 1 or a 7 please justify:

\section{Peer Review}

First Partner's Name:

Partner's grade: (Circle one in each category)

\begin{tabular}{|l|l|l|l|l|l|l|l|}
\hline Quality of Work: & 1 & 2 & 3 & 4 & 5 & 6 & 7 \\
\hline
\end{tabular}

\begin{tabular}{|l|l|l|l|l|l|l|l|l|}
\hline Team Membership: & 1 & 2 & 3 & 4 & 5 & 6 & 7 \\
\hline Com & 1 & 2 & 3 & 4 & 5 & 6 & 7 \\
\hline
\end{tabular}

\begin{tabular}{l|l|l|l|l|l|l|l|} 
Communications: & 1 & 2 & 3 & 4 & 5 & 6 & 7 \\
\hline
\end{tabular}

If you gave a 1 or a 7 please justify:

Second Partner's Name:

Partner's grade: (Circle one in each category)

\begin{tabular}{|l|l|l|l|l|l|l|l|}
\hline Quality of Work: & 1 & 2 & 3 & 4 & 5 & 6 & 7 \\
\hline Team Membership: & 1 & 2 & 3 & 4 & 5 & 6 & 7 \\
\hline
\end{tabular}

\begin{tabular}{l|l|l|l|l|l|l|l} 
Communications: & 1 & 2 & 3 & 4 & 5 & 6 & 7 \\
\hline
\end{tabular}

If you gave a 1 or a 7 please justify:

Third Partner's Name:

Partner's grade: (Circle one in each category)

\begin{tabular}{|l|l|l|l|l|l|l|l|}
\hline Quality of Work: & 1 & 2 & 3 & 4 & 5 & 6 & 7 \\
\hline Team & &
\end{tabular}

\begin{tabular}{l|l|l|l|l|l|l|l} 
Team Membership: & 1 & 2 & 3 & 4 & 5 & 6 & 7
\end{tabular}

\begin{tabular}{l|l|l|l|l|l|l|l}
\hline Communications: & 1 & 2 & 3 & 4 & 5 & 6 & 7 \\
\hline
\end{tabular}

If you gave a 1 or a 7 please justify:
Date:

ture:




\section{Member Effectiveness}

Identify relative contributions (\%) of each team member to project achievements this term. Each row should add up to $100 \%$.

\begin{tabular}{|l|l|l|l|l|l|}
\hline & \multicolumn{2}{|c|}{ Team Member Names } & \\
\hline & self & & & & total \\
\hline Project time invested by each member (\%)* & & & & & $100 \%$ \\
\hline Value added to project by each member (\%)*: & & & & & $100 \%$ \\
\hline
\end{tabular}

*Please explain any percentages that differ greatly from others. 
Strengths/Areas to Improve

\begin{tabular}{|c|c|c|}
\hline Name & Strength & Area to Improve \\
\hline $\begin{array}{l}\text { Example } \\
\text { John }\end{array}$ & $\begin{array}{l}\text { Strength: Dependability } \\
\text { Explanation: Always follows through on as- } \\
\text { signments. Produces work of quality. Enables } \\
\text { team members to focus on their own work. }\end{array}$ & $\begin{array}{l}\text { Area to Improve: Asking others for help } \\
\text { Suggestion: not necessary to take everything } \\
\text { on your own shoulders, ability to depend on } \\
\text { others in a team environment means team is a } \\
\text { must, motivating others means team will have } \\
\text { better resources to draw on }\end{array}$ \\
\hline self & $\begin{array}{l}\text { Strength: } \\
\text { Explanation: }\end{array}$ & $\begin{array}{l}\text { Area to Improve: } \\
\text { Suggestion: }\end{array}$ \\
\hline partner 1 & $\begin{array}{l}\text { Strength: } \\
\text { Explanation: }\end{array}$ & $\begin{array}{l}\text { Area to Improve: } \\
\text { Suggestion: }\end{array}$ \\
\hline partner 2 & $\begin{array}{l}\text { Strength: } \\
\text { Explanation: }\end{array}$ & $\begin{array}{l}\text { Area to Improve: } \\
\text { Suggestion: }\end{array}$ \\
\hline partner 3 & $\begin{array}{l}\text { Strength: } \\
\text { Explanation: }\end{array}$ & $\begin{array}{l}\text { Area to Improve: } \\
\text { Suggestion: }\end{array}$ \\
\hline
\end{tabular}

